\title{
Updated Priorities Among Effective Clinical Preventive Services
}

\author{
Michael V. Maciosek, $P b D$ \\ Amy B. LaFrance, MPH \\ Steven P. Debmer, $\mathrm{PbD}$ \\ Dana A. McGree \\ Thomas J. Flottemesch, PbD \\ Zack Xu, MS \\ Leif I. Solberg, $M D$ \\ HealthPartners Institute, Minneapolis, \\ Minnesota

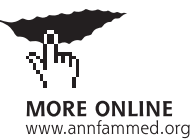

Conflicts of interest: authors report none.

\section{CORRESPONDING AUTHOR}

Michael V. Maciosek, PhD

HealthPartners Institute

Mail Stop 23301A

PO Box 1524

Minneapolis, MN 55440-1524,

michael.v.maciosek@healthpartners.com

\begin{abstract}
PURPOSE The Patient Protection and Affordable Care Act's provisions for firstdollar coverage of evidence-based preventive services have reduced an important barrier to receipt of preventive care. Safety-net providers, however, still serve a substantial uninsured population, and clinician and patient time remain limited in all primary care settings. As a consequence, decision makers continue to set priorities to help focus their efforts. This report updates estimates of relative health impact and cost-effectiveness for evidence-based preventive services.
\end{abstract}

METHODS We assessed the potential impact of 28 evidence-based clinical preventive services in terms of their cost-effectiveness and clinically preventable burden, as measured by quality-adjusted life years (QALYs) saved. Each service received 1 to 5 points on each of the 2 measures-cost-effectiveness and clinically preventable burden-for a total score ranging from 2 to 10 . New microsimulation models were used to provide updated estimates of 12 of these services. Priorities for improving delivery rates were established by comparing the ranking with what is known of current delivery rates nationally.

RESULTS The 3 highest-ranking services, each with a total score of 10, are immunizing children, counseling to prevent tobacco initiation among youth, and tobacco-use screening and brief intervention to encourage cessation among adults. Greatest population health improvement could be obtained from increasing utilization of clinical preventive services that address tobacco use, obesityrelated behaviors, and alcohol misuse, as well as colorectal cancer screening and influenza vaccinations.

CONCLUSIONS This study identifies high-priority preventive services and should help decision makers select which services to emphasize in quality-improvement initiatives.

Ann Fam Med 2017;15:14-22. https://doi.org/10.1370/afm.2017.

\section{INTRODUCTION}

The landscape for prevention in primary care has changed dramatically since the Committee on Clinical Preventive Service Priorities published the first ranking of clinical preventive services in 2001, ${ }^{1}$ and the National Commission on Prevention Priorities (NCPP) last updated the list in $2006 .^{2} \mathrm{~A}$ growing evidence base has expanded knowledge about effective preventive services. At the same time, the Patient Protection and Affordable Care Act (ACA) and the pursuit of the Triple $\mathrm{Aim}^{3}$ seek to expand access to and the efficiency of primary care.

Changes in primary care have potential to improve utilization of preventive services. Patient-centered medical homes (PCMHs) have been associated with increased use of preventive services, though it is not clear whether health and financial outcomes are affected. ${ }^{4-6}$ Accountable Care Organizations (ACOs), when combined with $\mathrm{PCMHs}$, may empower primary care and incentivize change, ${ }^{7}$ and ACO shared-savings contracts may encourage hospital systems and specialty providers to become vested stakeholders in evidence-based prevention. Preventive care quality measures and incentives in ACO contracts might assure that prevention is pri- 
oritized while participants pursue strategies to reduce the cost of care.

Since the release of the 2001 clinical preventive services ranking, the National Committee for Quality Assurance more than doubled the Healthcare Effectiveness Data and Information Set measures in primary and secondary prevention. ${ }^{8}$ In 2013 , the committee adopted these quality measures for ACOs, which include 9 measures for primary prevention and screening. ${ }^{9}$ In 2014 and 2015, it introduced measures to track unnecessary cervical cancer screening in adolescent females and unnecessary prostate cancer screening in older men, with the goal of reducing utilization and preventing harm. ${ }^{8,10}$

The ACA now mandates first-dollar coverage for evidence-based prevention in nongrandfathered plans, ${ }^{11}$ including grade $\mathrm{A}$ and $\mathrm{B}$ recommendations of the US Preventive Services Task Force (USPSTF). Evidence of increased utilization of preventive services associated with implementation of the ACA is beginning to emerge, particularly among persons aged 19 to 25 years as covered dependents in family insurance policies. Nearly 1 million additional women have received human papillomavirus vaccinations ${ }^{12}$ through expanded insurance coverage. From 2009 to 2011, hypertension screening, cholesterol screening, and annual dental visits increased among young adults, though influenza vaccinations did not. ${ }^{13}$ Early data hint at increased receipt of other preventive services for adults of all ages $^{14,15}$ as ACA provisions for expanded insurance coverage and no co-payments took effect.

Meanwhile, new knowledge is changing preventive service recommendations, which may alter our understanding of which services may produce highest value relative to each other. In the past decade, the Advisory Committee on Immunization Practices recommended hepatitis $\mathrm{A}$ and rotavirus immunizations for children, human papillomavirus and meningococcal immunizations for adolescents, influenza vaccinations for an expanded population to include all ages above 6 months, herpes zoster vaccine to prevent shingles in older adults, and the additional vaccines of both the tetanus-diphtheria booster and pneumococcal vaccinations for adults. In the same time frame, the USPSTF recommended new services or substantially expanded the recommended target population for 13 evidencebased preventive services while retiring 3 recommendations. The value of other recommended services may be affected by new technologies or new use of existing technologies, including human papillomavirus testing in conjunction with Papanicolaou screening, improvements in testing for human immunodeficiency virus, and offering varenicline to help smokers to quit.

In creating an updated priority list of evidencebased preventive services, we incorporated many of these new and revised recommended clinical preventive services to assist clinicians and other decision makers in their efforts to plan quality improvement initiatives, develop performance measurements, build primary care medical homes, and incorporate preventive services into $\mathrm{ACO}$ contracts.

\section{METHODS}

Methods were guided by the NCPP, a panel of health care clinicians, health insurance plan leaders, employers, government representatives, and academics. HealthPartners Institute conducted the analytical work.

\section{Included Preventive Services}

The clinical preventive services considered for this update included services recommended by the USPSTF for the general population that were given an A or B grade, Advisory Committee on Immunization Practices recommendations for the general population, and services recommended by the USPSTF for those at increased risk for cardiovascular disease (CVD) or sexually transmitted infections that were given an $\mathrm{A}$ or B grade. Services for the general population were defined as those for which the recommended population is limited only by age or sex criteria. Services that are routinely co-occurring, such as childhood vaccines, were evaluated as 1 service. For a more complete description of included and excluded services, see the Supplemental Appendix, available at http://www.annfammed.org/content/15/1/14/suppl/DC1.

\section{Measures and Estimation}

Preventive services were evaluated using 2 measures: clinically preventable burden as a measure of the health impact of a preventive service, and cost-effectiveness as a measure of efficiency. Clinically preventable burden is defined here as the total quality-adjusted life years (QALYs) that could be gained if the clinical preventive service were delivered at recommended intervals to a US birth cohort of 4 million patients over the years of life for which a service was recommended. Cost-effectiveness is the net cost per QALY gained. Estimation methods have been previously reported. ${ }^{16}$ Here we highlight new methods as well as methods that are key to interpreting results.

Using simulation models, the clinically preventable burden and cost-effectiveness were computed by comparing scenarios with no utilization of a service with a scenario in which the service was offered to $100 \%$ of the target population. The current burden of cervical cancer is low compared with what it would be without cervical cancer screening, as is the current burden of vaccine-preventable childhood infectious diseases. The 
total health benefit as calculated by clinically preventable burden in this manner reveals the overall importance of such services.

The clinically preventable burden and costeffectiveness estimates reflect scenarios with $100 \%$ of the target population offered each service, but not all accept or complete follow-up diagnostic testing, treatment, medication use, or behavior change necessary to benefit from the service. Realistic estimates of adherence were used to allow clinically preventable burden estimates to reflect differences in patient follow-through.

The literature for some services, such as mammography screening, provides data on the effectiveness of periodic utilization, and the literature for other services, such as tobacco cessation counseling, focuses on one-time use. Clinically preventable burden and cost-effectiveness are estimated with greater consistency across services through the use of modeling to estimate the cumulative benefit of multiple opportunities to utilize the service throughout the recommended age range. Clinically preventable burden and cost-effectiveness estimates reflect the impact of each service throughout the lifetime, including the delayed impact after the age when the service is no longer routinely offered.

QALYs are not discounted to present value in calculating clinically preventable burden, ${ }_{i}$ costs and QALYs, however, were discounted by 3\% per year in the cost-effectiveness ratio. Costs are either measured in or adjusted to 2012 US dollars.

In estimating cost-effectiveness, the principles of the reference case methods of the first Panel on Cost Effectiveness in Health and Medicine were followed to promote consistency with recognized best practices and consistency across services. ${ }^{17}$ In keeping with these methods, costs include quantitatively important medical costs for screening, counseling, pharmaceutical treatment, and follow-up diagnostic tests and treatments for both true- and false-positive screening findings. The value of a patient's time required to travel to the appointment and receive both the preventive service and needed follow-up was calculated using average hourly earnings for the United States. ${ }^{18}$ For visits in which more than the preventive service would be addressed, a fraction of a 15 -minute office visit and associated travel time were apportioned to the cost of the service. Potential savings included medical costs for avoided treatments or reduced costs for less-intensive, earlier-stage treatments. In keeping with the principles of the reference case methods, ${ }^{17}$ savings do not reflect potential productivity gains when using health utilities to calculate QALYs, because the health utilities may already reflect patient valuation of time lost.

New in this ranking is the use of HealthPartners Institute's ModelHealth microsimulation models to provide more precise estimates for preventive services with complex time elements, such as cancer screenings, CVD screenings, and repeated counseling related to diet, physical activity, and tobacco use. The microsimulation models tracked 500,000 or more simulated individuals in annual cycles over their lifetimes, both in scenarios with zero utilization and offering the preventive service to $100 \%$ of the target population. Twelve services in the ranking were estimated using microsimulation. Five of these are exemplified in the two accompanying articles on tobacco counseling and reducing other CVD risks. Other services were estimated either with spreadsheet models (13 services) or using existing peer-reviewed literature (3 services). The spreadsheet models assess the impact on a birth cohort as a whole over discrete age groups rather than by simulating individuals and tracking their status and outcomes year-by-year, as done in the microsimulation models. Literature-based estimates require adjustments to reported results to improve consistency across services in the ranking, such as inflation adjustment, adding time costs for receipt of preventive services, and calculations to convert the impact of a cross-sectional analysis to a birth cohort. Spreadsheet-based estimates often rely heavily on multiple published studies; therefore, spreadsheet and literature-based estimates represent a continuum of new calculations and use of modeled estimates from others. For example, our estimate for childhood immunizations - a literature-based estimate-uses model estimates from 2 other studies of the events prevented ${ }^{19}$ and the cost-savings, ${ }^{20}$ but uses information from additional sources to estimate QALYs saved and the costs of the vaccination series. Summaries of the methods for services are available online. ${ }^{21}$

\section{Service Scoring}

As with the prior ranking, the NCPP chose to group services with a similar clinically preventable burden or cost-effectiveness into 5 scoring categories for each measure to balance the goal of delineated services on value with the risk of overstating the precision of the estimates. ${ }^{22}$ Services were sorted in descending order of burden estimates and in ascending order of costeffectiveness ratios. The 28 included services are not divisible into 5 equally sized groups $;$ therefore, for each metric we identified groups of 5 and 6 services that maximized the percentage difference between estimates of the lowest estimate in the higher scoring category and the highest estimate in the lower scoring category. Services in the highest group were assigned a score of 5 , and services in the lowest group were assigned a score of 1 . Scores for clinically preventable burden and cost-effectiveness were then added to give each service a score ranging from 10 (best) to 2 (lowest). 
the Triple $\mathrm{Aim}^{3}$ — the NCPP has maintained an emphasis on value. Focusing on high-value clinical preventive services is one way clinicians and systems can deliver on the Triple Aim.
Since 2001 only 6 recommended preventive services changed their score by more than 1 point in our ranking (see the Supplemental Appendix). This finding should reassure clinicians and health care organiza-

\section{Table 2. Priorities for Improving Utilization of Clinical Preventive Services}

\begin{tabular}{|c|c|c|c|c|}
\hline Services (Short Name) & Description & CPB & CE & Total \\
\hline Childhood immunization series & ACIP childhood immunization series ${ }^{a}$ & 5 & 5 & 10 \\
\hline $\begin{array}{l}\text { Tobacco use, brief prevention } \\
\text { counseling, youth }\end{array}$ & Provide interventions to prevent initiation, including education or brief counseling & 5 & 5 & 10 \\
\hline $\begin{array}{l}\text { Tobacco use screening and } \\
\text { brief counseling, adults }\end{array}$ & $\begin{array}{l}\text { Screen adults for tobacco use and provide brief cessation counseling and } \\
\text { pharmacotherapy }\end{array}$ & 5 & 5 & 10 \\
\hline $\begin{array}{l}\text { Alcohol misuse screening and } \\
\text { brief intervention }\end{array}$ & Screen adults' misuse and provide brief counseling to reduce alcohol use & 3 & 5 & $8^{\mathrm{b}}$ \\
\hline $\begin{array}{l}\text { Aspirin chemoprevention for } \\
\text { those at higher risk of CVD }\end{array}$ & $\begin{array}{l}\text { Low-dose aspirin use for primary prevention of CVD in adults ages } 50-59 \text { y with } \\
\leq 10 \%, 10-y \text { CVD risk and other factors }\end{array}$ & 3 & 5 & 8 \\
\hline Cervical cancer screening & $\begin{array}{l}\text { Screen for cervical cancer in women aged } 21 \text { to } 65 \text { y with cytology (Papanicolaou } \\
\text { smear) every } 3 \text { y }\end{array}$ & 4 & 4 & 8 \\
\hline Colorectal cancer screening & Screen adults aged $50-75$ y routinely & 4 & 4 & $8^{b}$ \\
\hline $\begin{array}{l}\text { Chlamydia and gonorrhea } \\
\text { screening }\end{array}$ & $\begin{array}{l}\text { Screen for chlamydia and gonorrhea in sexually active women aged } \leq 24 \mathrm{y} \text {, and } \\
\text { in older women at increased risk for infection }\end{array}$ & 3 & 4 & $7^{\mathrm{b}}$ \\
\hline Cholesterol screening & $\begin{array}{l}\text { Screen routinely for lipid disorders men aged }>35 \text { y, and screen younger men } \\
\text { and women of all ages who are at increased risk of CHD. Treat with lipid- } \\
\text { lowering medications }\end{array}$ & 4 & 3 & 7 \\
\hline Hypertension screening & $\begin{array}{l}\text { Measure blood pressure routinely in all adults and treat with antihypertensive } \\
\text { medication to prevent the incidence of CVD }\end{array}$ & 4 & 3 & 7 \\
\hline AAA screening & $\begin{array}{l}\text { Screen men aged } 65-75 \text { y who have ever smoked } 1 \text { time for abdominal aortic } \\
\text { aneurysm, using ultrasonography }\end{array}$ & 2 & 4 & $6^{b}$ \\
\hline $\begin{array}{l}\text { Healthy diet and physical } \\
\text { activity counseling for those } \\
\text { at higher risk of CVD }\end{array}$ & $\begin{array}{l}\text { Offer or refer adults who are overweight or obese with additional CVD risk factors } \\
\text { to intensive behavioral counseling to promote healthful diet and physical activity }\end{array}$ & 5 & 1 & 6 \\
\hline HIV screening & $\begin{array}{l}\text { Screen for HIV infection in adolescents and adults aged } 15 \text { to } 65 \mathrm{y} \text {. Frequency } \\
\text { varies by risk level }\end{array}$ & 2 & 4 & $6^{\mathrm{b}}$ \\
\hline HPV immunization & Administer a 3-dose series of HPV vaccine to all girls aged $11-12$ y & 3 & 3 & 6 \\
\hline Influenza immunization, adults & Immunize all adults against influenza annually & 4 & 2 & $6^{b}$ \\
\hline Obesity screening, adults & $\begin{array}{l}\text { Screen all adults routinely for obesity. Refer patients with a BMI of } \geq 30 \mathrm{~kg} / \mathrm{m}^{2} \text { to } \\
\text { intensive behavioral interventions }\end{array}$ & 5 & 1 & $6^{\mathrm{b}}$ \\
\hline Syphilis screening & Screen all persons at increased risk for syphilis infection & 1 & 5 & 6 \\
\hline Vision screening, children & Screen children routinely between ages 3 and 5 y to detect amblyopia & 2 & 4 & $6^{b}$ \\
\hline Breast cancer screening & $\begin{array}{l}\text { Biennial mammography for women aged 50-74 y; screening before age } 50 \text { y an } \\
\text { individual decision }\end{array}$ & 3 & 2 & $5^{b}$ \\
\hline $\begin{array}{l}\text { Depression screening, } \\
\text { adolescents }\end{array}$ & $\begin{array}{l}\text { Screen adolescents aged } 12-18 \text { y for depression with systems to assure accurate } \\
\text { diagnosis, treatment, and follow-up }\end{array}$ & 2 & 3 & $5^{b}$ \\
\hline Depression screening, adults & $\begin{array}{l}\text { Screen adults for depression with systems to assure accurate diagnosis, treatment, } \\
\text { and follow-up }\end{array}$ & 3 & 2 & $5^{b}$ \\
\hline $\begin{array}{l}\text { Obesity screening, children } \\
\text { and adolescents }\end{array}$ & $\begin{array}{l}\text { Screen children aged } \geq 6 \text { y for obesity. Offer or refer obese children to compre- } \\
\text { hensive, intensive behavioral intervention }\end{array}$ & 4 & 1 & 5 \\
\hline $\begin{array}{l}\text { Pneumococcal immunization, } \\
\text { adults }\end{array}$ & $\begin{array}{l}\text { Immunize adults aged }>65 \text { y against pneumococcal disease with PCV13 and } \\
\text { PPSV23 }\end{array}$ & 2 & 3 & $5^{b}$ \\
\hline Herpes zoster immunization & Single dose of vaccine for adults aged $>60 y$ & 1 & 3 & 4 \\
\hline Osteoporosis screening & $\begin{array}{l}\text { Screen women aged }>65 \text { y and younger women whose fracture risk is equal to } \\
\text { or greater than that of white women aged } 65 \text { y with no additional risk factors }\end{array}$ & 2 & 2 & 4 \\
\hline Folic acid chemoprevention & $\begin{array}{l}\text { Women planning or capable of pregnancy should take a daily supplement with } \\
0.4-0.8 \mathrm{mg} \text { of folic acid }\end{array}$ & 1 & 2 & 3 \\
\hline Meningococcal immunization & $\begin{array}{l}\text { Single dose of quadrivalent vaccine recommended for children aged } 11 \text { to } 12 \mathrm{y} \text {, } \\
\text { with a booster at age } 16 \mathrm{y}\end{array}$ & 1 & 1 & 2 \\
\hline Tdap/Td booster & One time Tdap and Td booster every 10 y & 1 & 1 & 2 \\
\hline
\end{tabular}

$\mathrm{AAA}=$ abdominal aortic aneurysm; $\mathrm{ACIP}=$ Advisory Committee on Immunization Practices; $\mathrm{BMI}=$ body mass index; $\mathrm{CE}=$ cost-effectiveness; $\mathrm{CHD}=$ coronary heart disease; $C P B=$ clinically preventable burden; $C V D=$ cardiovascular disease; HIV = human immunodeficiency virus; HPV = human papillomavirus; $P C V 13=$ pneumococcal conjugate vaccine -13 pneumococcal serotypes; PPSV23 = pneumococcal polysaccharide vaccine -23 pneumococcal serotypes; Td = tetanus, diphtheria; Tdap = tetanus, diphtheria, and pertussis.

a Estimate includes all recommended vaccines up to 10 years of age (diphtheria, tetanus, pertussis; measles, mumps, rubella; inactivated polio virus; Hemophilus influenzae type b; hepatitis $\mathrm{A}$; hepatitis $\mathrm{B}$; varicella; pneumococcal conjugate; influenza; and rotavirus) plus influenza vaccination to age 18 years.

b Sensitivity analysis indicated that a change of score of 2 or more is possible. 
tions that expend substantial energy and resources to incorporate the results of this ranking into quality improvement efforts. New to the top of the priority list is brief counseling to prevent tobacco initiation among youth. As with other services aimed at improving health behaviors, our model estimates indicate that the seemingly small success rate-measured by changing lifestyles of a small percentage of patients-has large long-term effects when the health behaviors have extensive health consequences. There remains substantial opportunity for primary care to improve popula- tion health through increasing the utilization of these evidence-based services.

In the 2006 ranking, increasing colorectal cancer screening rates stood out as an opportunity to improve health by increasing utilization. National screening rates for colorectal cancer have climbed markedly in the intervening years. Continued health gains are possible by further reducing the gap between colorectal cancer screening rates and screening rates for CVD risk factors and other cancers.

Individual clinicians, medical groups, and health

Table 3. QALYs Saved if Utilization Rates Increase Above Current Levels

\begin{tabular}{|c|c|c|c|}
\hline Services (Short Name) ${ }^{a}$ & Source & $\begin{array}{c}\text { Currently Receiving } \\
\text { Services Nationally } \\
\%\end{array}$ & $\begin{array}{l}\text { Additional QALY Saved if } \\
\text { Currently Receiving Services } \\
\text { Increased to } 90 \%{ }^{c}\end{array}$ \\
\hline \multicolumn{4}{|l|}{ Services with utilization data available } \\
\hline Tobacco use counseling to prevent initiation by youth ${ }^{d}$ & Jamal 23 & 20 & 530,000 \\
\hline $\begin{array}{l}\text { Tobacco use screening and brief cessation intervention, } \\
\text { adults }\end{array}$ & $\begin{array}{l}\text { NCQA }^{24} \\
\text { Jamal }^{25} \\
\text { King }^{26}\end{array}$ & 50 & 460,000 \\
\hline Alcohol misuse screening, brief intervention & McKnight-Eily ${ }^{27}$ & 10 & 140,000 \\
\hline Colorectal cancer screening & $\mathrm{CDC}^{28}$ & 65 & 110,000 \\
\hline Influenza immunization, adults & $\operatorname{CDC}^{29}$ & 45 & 100,000 \\
\hline HPV immunization ${ }^{d}$ & Reagan-Steiner ${ }^{30}$ & 50 & 59,000 \\
\hline Breast cancer screening & $\begin{array}{l}\mathrm{NCHS}^{31} \\
\mathrm{CDC}^{28}\end{array}$ & 75 & 42,000 \\
\hline Chlamydia and gonorrhea screening ${ }^{d}$ & $\mathrm{CDC}^{32}$ & 40 & 39,000 \\
\hline HIV screening & Chandra ${ }^{33}$ & 20 & 32,000 \\
\hline Aspirin chemoprevention for those at higher risk of CVD & Williams $^{34}$ & 50 & 30,000 \\
\hline Cervical cancer screening & $\begin{array}{l}\mathrm{NCHS}^{31} \\
\mathrm{CDC}\end{array}$ & 85 & 14,000 \\
\hline Vision screening, children & Kemper 35 & 75 & 5,000 \\
\hline Pneumococcal immunization, adults & $\mathrm{CDC}^{28}$ & 70 & 4,000 \\
\hline \multicolumn{4}{|l|}{ Services with utilization data assigned at 50\% } \\
\hline Obesity screening, adultse & Assigned & 50 & 540,000 \\
\hline Healthy diet counseling for those at higher risk of CVDe & Assigned & 50 & 300,000 \\
\hline Obesity screening, children and adolescents ${ }^{\mathrm{d}, \mathrm{e}}$ & Assigned & 50 & 78,000 \\
\hline Depression screening, adults ${ }^{e}$ & $\begin{array}{l}\text { Assigned } \\
\text { Farr }^{36} \\
\text { Edwards }^{37}\end{array}$ & 50 & 45,000 \\
\hline AAA screeninge & $\begin{array}{l}\text { Assigned } \\
\text { Shreibati }\end{array}$ & 50 & 21,000 \\
\hline Depression screening, adolescents ${ }^{d, e}$ & Assigned & 50 & 11,000 \\
\hline Syphilis screeninge & Assigned & 50 & 2,000 \\
\hline \multicolumn{4}{|c|}{ 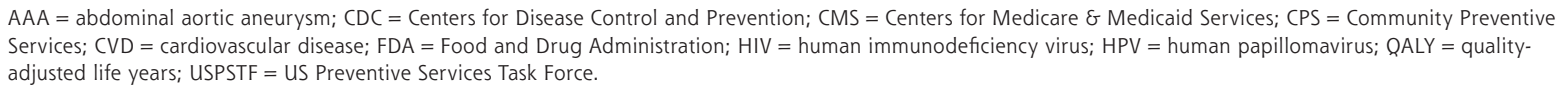 } \\
\hline \multicolumn{4}{|c|}{$\begin{array}{l}\text { a See Table } 2 \text { for a description of each service. Childhood immunizations, hypertension screening, and cholesterol omitted from table because of current high utilization } \\
\text { rates. } \\
\text { b Current utilization rates rounded and reflect approximate average of male and female patients, across all relevant age-groups and other important groups for a ser- } \\
\text { vice, such as groups at high and low risk for disease. } \\
\text { 'Indicates additional lifetime QALYs saved if } 90 \% \text { of a cohort of } 4 \text { million were offered service as recommended. } \\
\text { d Youth services estimated based on a target of } 90 \% \text { of youth receiving service annually, although slightly less than } 90 \% \text { of adolescents aged } 12-17 \text { years saw a health } \\
\text { care professional in } 2012 \text {. } \\
\text { e Based on limited utilization data. Utilization data were considered limited if existing information was difficult to use to quantify utilization rates and place an upper } \\
\text { boundary more precise than } 50 \% \text {. Either utilization data are completely lacking or are available only for a population for which generalizability to US population is } \\
\text { highly questionable, or the utilization measures available are poorly aligned with the preventive service as recommended by the USPSTF. }\end{array}$} \\
\hline
\end{tabular}


systems should review preventive service utilization rates of the populations they serve to identify opportunities to reduce delivery gaps at the local level. By comparing local utilization rates to the ranking in Table 2, while accounting for age and risk characteristics of the populations they serve, local decision makers can identify their own opportunities for improving patients' health. We also encourage decision makers to assess local disparities in utilization of high-priority services and tailor care processes to close gaps. Priorities may also vary at the individual patient characteristics, ${ }^{39}$ requiring clinician and patient judgment in defining individualized priorities.

Community-based organizations also have a role to play in closing gaps. For example, the Community Preventive Services Task Force in 2015 recommended implementing and maintaining school-based health centers in low-income communities. Several of those outcomes are relevant to the preventive services in this ranking, including increases in immunizations and reductions in tobacco smoking and alcohol use. ${ }^{40} \mathrm{An}$ integrated program that strategically combines the efforts of clinics and community-based organizations may efficiently produce greater impact.

It is important not to oversimplify the complex factors that contribute to changes in the rankings. For example, estimates of greater-than-expected impact from the food fortification program introduced in $1998^{41,42}$ reduced the potential impact of folic acid supplements, resulting in a drop in total score from 5 in 2006 to 3 in 2016. Another example is pneumococcal vaccine. Introduction of the 13 -valent pneumococcal conjugate (PCV13) vaccine in the childhood immunization series had a substantial impact on disease incidence in older adults, reducing the impact of the adult pneumococcal vaccine. Addition of the more costly PCV13 vaccine ${ }^{43}$ for adults in 2014 also reduced the overall cost-effectiveness of pneumococcal vaccinations for older adults.

The accuracy of our results is limited by factors common to modeling studies. Models cannot generate estimates that are more accurate than the data for influential variables that enter the model. Further, by definition, models simplify the complex chain of causation and associations present in the real world. Consequently, different decisions about building a model structure that fits the available data while representing key dependencies could yield different results.

Other limitations of the methods previously noted $^{2,16,22}$ are worth mention. The ranking adds scores for 2 ordinal measures, clinically preventable burden and cost-effectiveness, and weights them equally to derive a total score. This method may not produce an ordering of total scores that matches the criteria impor- tant to a decision maker. We provide the separate scores for clinically preventable burden and cost-effectiveness, which can be weighted to derive an alternate order of services. These 2 measures were chosen as comprehensive metrics that indicate 2 important aspects of health services: health impact and efficiency. Other factors not reflected in these metrics-such as the impact on reducing health disparities, costs of systems to increase utilization, reimbursement, and publicly reported performance measurement—-should be considered alongside these rankings in setting priorities.

We followed the reference case methods of the first Panel on Cost Effectiveness in Health and Medicine. ${ }^{17}$ Updated recommendations from the second panel were released after all analyses were complete. The new recommendations suggest that productivity gains should be included in cost-effectiveness analysis conducted from the societal perspective and that a second reference case from the health system perspective be presented. ${ }^{44}$ Following the first panel's methods, we included patient time costs in receiving services. Doing so particularly affects the costeffectiveness of services that include intensive weight management as a key part of follow-up. Relative to other services in the ranking, those preventive services likely would score higher on cost-effectiveness that is conducted from the health systems perspective. Adding productivity gains to all services in analysis from the societal perspective may not substantially change the services' relative rankings, but we could not fully assess adding the gains for this update.

Our analysis includes only a fraction of services among which priorities for clinic time and resources must be made. It is useful to consider these rankings in a broader context. Relative differences exist in the benefits that can be achieved through more consistent use of these services; all of these services, however, have proven value in prevention and should be prioritized over services with less or no evidence. A much larger portion of primary care time is spent on diagnosis and treatment. We are not aware of any effort to begin the enormous task of discerning priorities among the whole range of medical care services. Evidence-based preventive services for higher-risk groups may be very important for those groups and are not included in our ranking. Effective community preventive services also are not included. As hospitals look for options to meet community health benefits and to help manage population health as part of accountable care organizations, they can look to resources, such as the Guide to Community Preventive Services,${ }^{45}$ County Health Rankings and Road Maps, ${ }^{46}$ and the Community Health Advisor, ${ }^{47}$ for guidance on evidence-based community preventive services. 
This update does not include 4 services, listed in the Supplemental Appendix that meet our conceptual scope. An effort of this magnitude requires ongoing work to keep pace with important changes to the evidence base, underlying data, and new recommendations. We intend to develop a process of continuous updates, with incremental updates made available in a timely manner.

Recognizing these limitations, decision makers can use this ranking tool as they continue efforts to improve quality of care in a changing primary care environment. First-dollar coverage for preventive services and expanded insurance coverage through the ACA, the pursuit of the Triple Aim, and creation of PCMHs may each contribute to increased utilization of clinical preventive services. No single initiative, however, has been shown to dramatically increase utilization rates by itself. This timely update can be used to guide decisions to make the most of the opportunities presented by changes in how primary care is provided.

To read or post commentaries in response to this article, see it online at http://www.annfammed.org/content/15/1/14.

Key words: disease, prevention $\&$ control; health services; economics; prioritization; health impact; cost-effectiveness; cost-savings; immunization; mass screening; behavioral counseling

Submitted April 19, 2016; submitted, revised, September 16, 2016; accepted October 9, 2016.

Funding support: Support for this study was received from the Centers for Disease Control and Prevention (Cooperative Agreement Numbers 5H25PS003610 and U58/CC0322077-02-01), Robert Wood Johnson Foundation, WellPoint (now Anthem) Foundation, HealthPartners Institute for Education and Research, and American Heart Association.

Disclaimer: The contents are solely the responsibility of the authors and do not necessarily represent the official views of the Centers for Disease Control and Prevention.

Previous presentations: Draft presented during private webinar of the National Commission on Prevention Priorities on Nov 13, 2015, CDC staff on Apr 14, 2016 and Oct 18, 2016, AHRQ staff on July 11, 2016, and at the APHA Annual Meeting Nov 2, 2016.

Acknowledgments: We are grateful for the guidance of the National Commission on Prevention Priorities: Eduardo Sanchez, MD, MPH (Chair); Kim Barnhill, MS, MPH; Ross C. Brownson, PhD; Michael C. Caldwell, MD, MPH; Jonathan E. Fielding, MD, MPH, MBA; David W. Fleming, MD; Anne C. Haddix, PhD; George Isham MD; Lovell Jones, PhD; Warren A. Jones, MD, FAAFP; Linda Kinsinger, MD, MPH; Samuel Nussbaum, MD; C. Tracy Orleans, PhD; Marcel Salive, MD, MPH; Steven L. Solomon, MD; Kurt C. Stange, MD, PhD; Steven M. Teutsch, MD, MPH; Cristie Upshaw Travis, MS; Stephen Williams, MEd, MPA; and Steven H. Woolf, MD, MPH. We thank Louise Anderson, PhD; Ashley Coffield, MPA; Nichol Edwards, MS, Jennifer Jenson, MPH, MPP; Brian Martinson, PhD; Barbara Olson-Bullis, MA; and John Schousboe, MD, $\mathrm{MPH}$, for the expertise they provided in project guidance, literature review, and analysis.
Supplementary materials: Available at http://www.AnnFamMed. org/content/15/1/14/suppl/DC1/.

\section{References}

1. Coffield AB, Maciosek MV, McGinnis JM, et al. Priorities among recommended clinical preventive services. Am J Prev Med. 2001; 21(1):1-9.

2. Maciosek MV, Coffield AB, Edwards NM, Flottemesch TJ, Goodman MJ, Solberg LI. Priorities among effective clinical preventive services: results of a systematic review and analysis. Am J Prev Med. 2006;31(1):52-61.

3. Berwick DM, Nolan TW, Whittington J. The Triple Aim: care, health, and cost. Health Aff (Millwood). 2008;27(3):759-769.

4. Jackson GL, Powers BJ, Chatterjee R, et al. Improving patient care. The patient centered medical home. A Systematic Review. Ann Intern Med. 2013;158(3):169-178.

5. Ferrante JM, Balasubramanian BA, Hudson SV, Crabtree BF. Principles of the patient-centered medical home and preventive services delivery. Ann Fam Med. 2010;8(2):108-116.

6. Markovitz AR, Alexander JA, Lantz PM, Paustian ML. Patientcentered medical home implementation and use of preventive services: the role of practice socioeconomic context. JAMA Intern Med. 2015;175(4):598-606

7. Rittenhouse DR, Shortell SM, Fisher ES. Primary care and accountable care-two essential elements of delivery-system reform. $N$ Engl J Med. 2009;361(24):2301-2303.

8. National Committee for Quality Assurance. The Healthcare Effectiveness Data and Information Set (HEDIS) \& Performance Measurement. http://www.ncqa.org/HEDISQualityMeasurement.aspx. Published 2015. Accessed Jul 28, 2015.

9. National Committee for Quality Assurance, The Healthcare Effectiveness Data and Information Set (HEDIS). Accountable care organization core measures. http://www.ncqa.org/Portals/0/HEDISQM/ HEDIS2013/ACO_Core_Measure_List_9.6.12.pdf. Published 2013. Accessed Jul 28, 2015.

10. National Committee for Quality Assurance. NCQA updates HEDIS measures. http://www.ncqa.org/Newsroom/ NewsArchive/2013NewsArchive/NewsReleaseJuly32013.aspx. Published 2013. Accessed Nov 11, 2015.

11. United States Department of Health and Human Services. Coverage of preventive health services. Code of Federal Regulations Title 45:147.130: 691-693-2011. https://www.gpo.gov/fdsys/granule/CFR2011-title45-vol1/CFR-2011-title45-vol1-sec147-130/content-detail. html.

12. Lipton BJ, Decker SL. ACA Provisions associated with increase in percentage of young adult women initiating and completing the HPV vaccine. Health Aff (Millwood). 2015;34(5):757-764.

13. Lau JS, Adams SH, Park MJ, Boscardin WJ, Irwin CE Jr. Improvement in preventive care of young adults after the affordable care act: the affordable care act is helping. JAMA Pediatr. 2014;168(12):1101-1106.

14. Han X, Robin Yabroff K, Guy GP Jr, Zheng Z, Jemal A. Has recommended preventive service use increased after elimination of costsharing as part of the Affordable Care Act in the United States? Prev Med. 2015;78:85-91.

15. Fedewa SA, Goodman M, Flanders WD, et al. Elimination of costsharing and receipt of screening for colorectal and breast cancer. Cancer. 2015;121(18):3272-3280.

16. Maciosek MV, Edwards NM, Coffield AB, et al. Priorities among effective clinical preventive services: methods. Am J Prev Med. 2006;31(1):90-96.

17. Gold MR, Siegel JE, Russell LB, Weinstein MC, eds. Cost-Effectiveness in Health and Medicine. New York, NY: Oxford University Press; 1996. 
18. Employer costs for employee compensation - September 2012 [press release]. Washington, DC: Bureau of Labor Statistics; December 11, 2012. http://www.bls.gov/news.release/archives/ ecec_12112012.pdf.

19. Whitney CG, Zhou F, Singleton J, Schuchat A; Centers for Disease Control and Prevention (CDC). Benefits from immunization during the vaccines for children program era - United States, 1994-2013. MMWR Morb Mortal Wkly Rep. 2014;63(16):352-355.

20. Zhou F, Shefer A, Wenger J, et al. Economic evaluation of the routine childhood immunization program in the United States, 2009. Pediatrics. 2014;133(4):577-585.

21. Healthpartners Institute. National Commission on Prevention Priorities. https://www.healthpartners.com/hprf/institute-ncpp/index.html.

22. Maciosek MV, Coffield AB, McGinnis JM, et al. Methods for priority setting among clinical preventive services. Am J Prev Med. 2001;21(1):10-19.

23. Jamal A, Dube SR, Babb SD, Malarcher AM; Centers for Disease Control and Prevention (CDC). Tobacco use screening and cessation assistance during physician office visits among persons aged 11-21 years-National Ambulatory Medical Care Survey, United States, 2004-2010. MMWR Suppl. 2014;63(2):71-79.

24. National Committee for Quality Assurance. Medical Assistance with Smoking and Tobacco Use Cessation 2015. http://www.ncqa.org/ report-cards/health-plans/state-of-health-care-quality/2016-table-ofcontents/smoking-cessation. Accessed Nov 9, 2015.

25. Jamal A, Dube SR, Malarcher AM, Shaw L, Engstrom MC; Centers for Disease Control and Prevention (CDC). Tobacco use screening and counseling during physician office visits among adults-National Ambulatory Medical Care Survey and National Health Interview Survey, United States, 2005-2009. MMWR Suppl. 2012;61(2)(Suppl):38-45.

26. King BA, Dube SR, Babb SD, McAfee TA. Patient-reported recall of smoking cessation interventions from a health professional. Prev Med. 2013;57(5):715-717.

27. McKnight-Eily LR, Liu Y, Brewer RD, et al.; Centers for Disease Control and Prevention (CDC). Vital signs: communication between health professionals and their patients about alcohol use -44 states and the District of Columbia, 2011. MMWR Morb Mortal Wkly Rep. 2014;63(1):16-22.

28. Centers for Disease Control and Prevention. Behavioral Risk Factor Surveillance System. Atlanta, GA: Centers for Disease Control and Prevention, US Dept of Health and Human Services. http://www. cdc.gov/brfss/. Accessed Nov 9, 2015.

29. Centers for Disease Control and Prevention. Flu vaccination coverage, United States, 2012-13 influenza season. http://www.cdc.gov/ flu/pdf/fluvaxview/vax-coverage-1213estimates.pdf. Updated Sep 25, 2013. Accessed Nov 9, 2015.

30. Reagan-Steiner S, Yankey D, Jeyarajah J, et al. National, regional, state, and selected local area vaccination coverage among adolescents aged 13-17 years-United States, 2014. MMWR Morb Mortal Wkly Rep. 2015;64(29):784-792.

31. Health, United States, 2014: With Special Feature on Adults Aged 55-64. Hyattsville, MD: National Center for Health Statistics: 2015.

32. Centers for Disease Control and Prevention. Sexually Transmitted Disease Surveillance, 2014. Atlanta, GA: Centers for Disease Control and Prevention, US Dept of Health and Human Services. http://www. cdc.gov/std/stats14/surv-2014-print.pdf. Published 2015. Accessed Nov 9, 2015.
33. Chandra A, Billioux VG, Copen CE, Balaji A, DiNenno E. HIV testing in the U.S. household population aged 15-44: data from the National Survey of Family Growth, 2006-2010. Natl Health Stat Report. 2012;(58):1-26.

34. Williams CD, Chan AT, Elman MR, et al. Aspirin use among adults in the U.S.: results of a national survey. Am J Prev Med. 2015;48(5):501-508.

35. Kemper AR, Crews JE, Strickland B, Saaddine JB; Centers for Disease Control and Prevention (CDC). Vision screening among children aged 6 years-Medical Expenditure Panel Survey, United States, 2009-2010. MMWR Suppl. 2014;63(2):43-46.

36. Farr SL, Dietz PM, Williams JR, Gibbs FA, Tregear S. Depression screening and treatment among nonpregnant women of reproductive age in the United States, 1990-2010. Prev Chronic Dis. 2011; 8(6):A122.

37. Edwards JB, Tudiver F. Women's preventive screening in rural health clinics. Womens Health Issues. 2008;18(3):155-166.

38. Shreibati JB, Baker LC, Hlatky MA, Mell MW. Impact of the Screening Abdominal Aortic Aneurysms Very Efficiently (SAAAVE) Act on abdominal ultrasonography use among Medicare beneficiaries. Arch Intern Med. 2012;172(19):1456-1462.

39. Taksler GB, Keshner M, Fagerlin A, Hajizadeh N, Braithwaite RS. Personalized estimates of benefit from preventive care guidelines: a proof of concept. Ann Intern Med. 2013;159(3):161-168.

40. Community Preventive Services Task Force. Promoting Health Equity Through Education Programs and Policies: Effectiveness of School-Based Health Centers in Improving Educational and Health Outcomes. Health Equity: Education Programs and Policies http://www. thecommunityguide.org/healthequity/education/schoolbasedhealthcenters.html.

41. United States Food and Drug Administration. Food standards: Amendment of standards of identity for enriched grain products to require addition of folic acid. Fed Regist. 1996;61(44):8781-8797. https://www.gpo.gov/fdsys/pkg/FR-1996-03-05/pdf/96-5014.pdf.

42. Williams LJ, Rasmussen SA, Flores A, Kirby RS, Edmonds LD. Decline in the prevalence of spina bifida and anencephaly by race/ ethnicity: 1995-2002. Pediatrics. 2005;116(3):580-586.

43. Center for Medicare \& Medicaid Services. Payment Allowance Limits for Medicare Part B Drugs. https://www.cms.gov/Medicare/ Medicare-Fee-for-Service-Part-B-Drugs/McrPartBDrugAvgSalesPrice/ 2012ASPFiles.html. Published Oct 2012. Accessed Oct 10, 2015.

44. Sanders GD, Neumann PJ, Basu A, et al. Recommendations for conduct, methodological practices, and reporting of cost-effectiveness analyses: 2 nd panel on cost-effectiveness in health and medicine. JAMA. 2016;316(10):1093-1103.

45. Community Preventive Services Task Force. Guide to Community Preventive Services. Behavioral and social approaches to increase physical activity: enhanced school-based physical education. https:// www.thecommunityguide.org/sites/default/files/PA-BehavioralSchool-based-PE-Archive.pdf. Published 2000. Updated Jan 16, 2014.

46. County Health Rankings and Roadmaps. http://www.countyhealthrankings.org/. Accessed Nov 22, 2013.

47. Maciosek MV, Flottemesch TJ, Dehmer SP, LaFrance AB, McGree DA, O'Blenes SM. Community Health Advisor. 2015. http://www. communityhealthadvisor.org/drupal/cha/home. 